\title{
Effect of High Pressure Heat Treatment on Microstructure and Thermal Expansion Coefficients of Cu-Al Alloy
}

\author{
Ma Yu-quan \\ Mechanical and Electrical Engineering College, Hebei Normal University of Science and Technology, Qinhuangdao 066004, China
}

With different high pressure heat treatments on $\mathrm{Cu}-\mathrm{Al}$ alloy, the effects on microstructure and thermal expansion coefficients of $\mathrm{Cu}-\mathrm{Al}$ alloy are studied in the paper by optical microscopy, scanning electron microscopy, transmission electron microscopy and expansion instrument etc. The experimental results show that after heat treatment, the structure of $\mathrm{Cu}-\mathrm{Al}$ alloy was refined obviously and the compactness increased. The grain refinement effect increases at first and then decreases when pressure is increased. When the pressure is $3 \mathrm{GPa}$, the most obvious is the thinning grain effect. In addition, the high pressure heat treatment can increase $\mathrm{Cu}-\mathrm{Al}$ alloy thermal coefficient of expansion, when the $\mathrm{Cu}-\mathrm{Al}$ alloy is treated by $3 \mathrm{GPa}$ pressure and is at $596.37^{\circ} \mathrm{C}$. Thermal expansion coefficient is the biggest, $3.1187 \times 10^{-5 \circ} \mathrm{C}^{-1}$, than that of the same temperature cast state samples increase 99.34\%. [doi:10.2320/matertrans.M2012358]

(Received October 26, 2012; Accepted January 25, 2013; Published March 25, 2013)

Keywords: copper-aluminum alloy, high pressure heat treatment, microstructure, thermal expansion coefficient

\section{Introduction}

$\mathrm{Cu}-\mathrm{Al}$ alloy has been widely used in shipping, machinery, aviation and other related fields due to its high strength, corrosion resistance, excellent hot and cold processing performance. However, the coarse grains of this material restrict its further application. ${ }^{1)}$ It is known that high pressure can promote the nucleation, but reduce the atomic diffusion coefficient and thus restrain the grain growth. ${ }^{2,3)}$ Therefore, the researches on the improvements of microstructure and properties of metal materials by means of high pressure heat treatment attracted considerable research interest. ${ }^{4,5}$ ) High pressure treatment has been found to be effective in improving the microstructure and mechanical properties of $\mathrm{Cu}$ alloys. ${ }^{6-8)}$ However, studies on the effect of high press treatment on the thermal expansion property of $\mathrm{Cu}$ alloys have not been reported yet. Furthermore, the service condition for metal parts often involves the combination of thermal-dynamic coupling filed, and thus it is necessary to carry out study on the effect of high pressure heat treatment on the microstructure and thermal expansion of $\mathrm{Cu}-\mathrm{Al}$ alloy. The results reported in this paper could provide basic reference for future application of high pressure heat treatment.

\section{Experiment}

The tested material was cast $\mathrm{Cu}-\mathrm{Al}$ alloy whose chemical composition (mass fraction, \%) is $84.67 \% \mathrm{Cu}, 10.64 \% \mathrm{Al}$, $2.65 \% \mathrm{Fe}, 1.58 \% \mathrm{Mn}, 0.46 \%$ others. The samples were sealed in a graphite sleeve, and the sleeve has been embedded into the pyrophyllite mould which serves as the pressure transmitting medium. Consequently, the mould was placed into the high pressure cell of CS-IB type six-anvil high-pressure equipment as shown in Fig. 1. High pressure heat treatment involves three values: 1,3 and $6 \mathrm{GPa}$. The samples were held at $750^{\circ} \mathrm{C}$ under pressure for $10 \mathrm{~min}$ and subsequently cooled to room temperature by cutting off the power supply with the holding pressure unchanged. Finally, the pressure was taken off. The samples before and after high pressure treatment

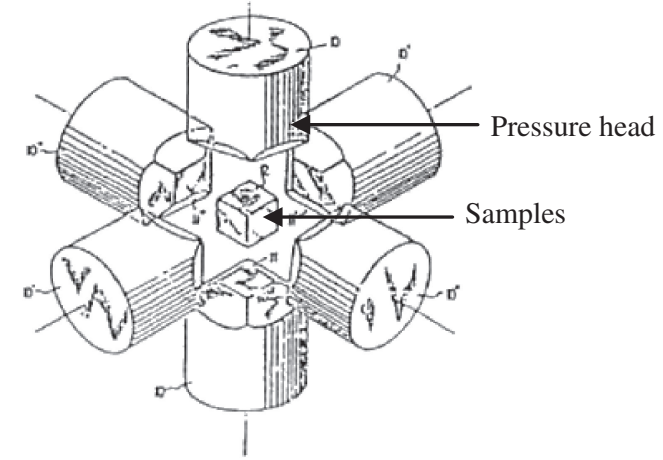

Fig. 1 Schematic map of pressure applying on sample.

were shaped into the size of $\phi 6 \mathrm{~mm} \times 15 \mathrm{~mm}$ by electronic spark cutting, and polished with 1200\# sandpaper. The thermal expansion coefficient of sample in the temperature range of $25-650^{\circ} \mathrm{C}$ were measured using a DIL $402 \mathrm{C}$ thermal expansion instrument (using $\mathrm{Al}_{2} \mathrm{O}_{3}$ as reference and the precision is $3 \%$ ) with a heating rate of $5^{\circ} \mathrm{C} / \mathrm{min}$ under protecting of argon atmosphere. The coefficient $\alpha=\Delta L /$ $(L \cdot \Delta T)$, where $\alpha, L, \Delta L$ and $\Delta T$ stands for linear expansion coefficient, sample length, linear expansion of the sample and the measured temperature range, respectively. To study the phase transformation of the $\mathrm{Al}-\mathrm{Cu}$ alloy during the temperature range of $25-650^{\circ} \mathrm{C}$, the thermal analyses were performed on a STA449C differential scanning calorimeter (DSC) for the samples (heated to $700^{\circ} \mathrm{C}$ with a heating rate of $5^{\circ} \mathrm{C} / \mathrm{min}$ ) before and after high pressure heat treatment. The microstructure of the samples was characterized by Axiovert 200MAT optical microscope, HATACHI S-3400N scanning electron microscope (SEM-BSE) and a JEOL-2010 transmission electron microscope (TEM).

\section{Results and Discussion}

\subsection{Microstructure}

Figure 2 shows the microstructure of $\mathrm{Cu}-\mathrm{Al}$ alloy before and after high pressure treatment. It can be seen that the microstructure of as-cast $\mathrm{Cu}-\mathrm{Al}$ alloy was coarse. The $\alpha$ 

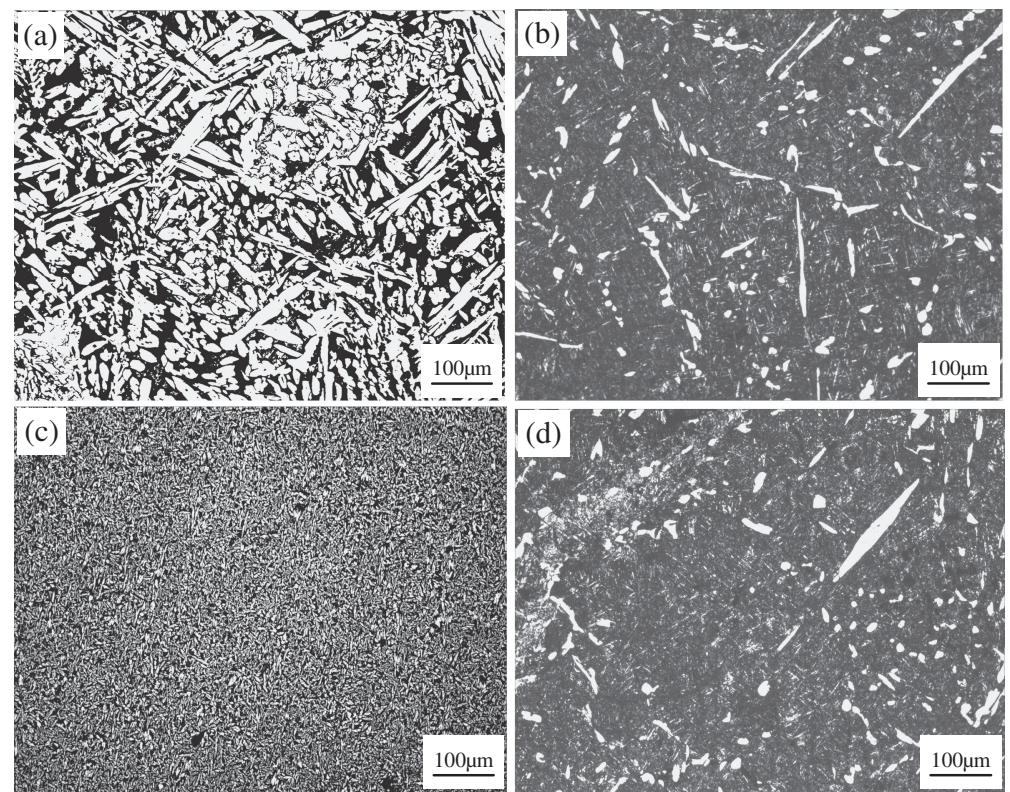

Fig. 2 Microstructure of $\mathrm{Cu}-\mathrm{Al}$ alloy [(a) As-cast; (b) $1 \mathrm{GPa}$; (c) $3 \mathrm{GPa}$; (d) $6 \mathrm{GPa}$.

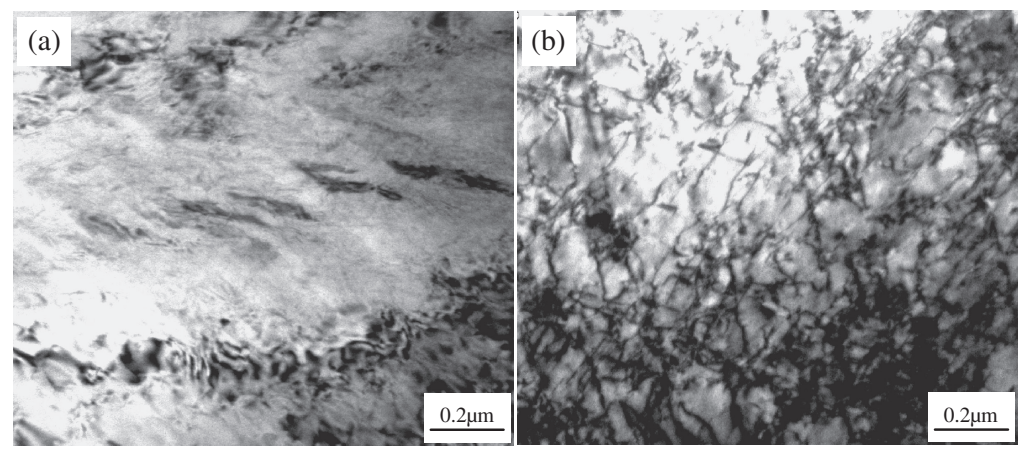

Fig. 3 TEM images of $\mathrm{Cu}-\mathrm{Al}$ alloy before and after high pressure treatment. [(a) As-cast; (b) $3 \mathrm{GPa}$.

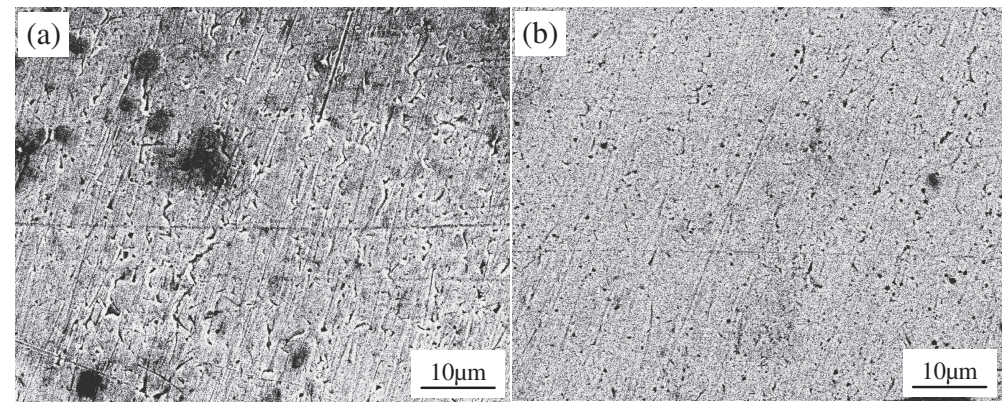

Fig. 4 SEM-BSE images of $\mathrm{Cu}-\mathrm{Al}$ alloy [(a) As-cast; (b) $3 \mathrm{GPa}$.

phase exists in strip pattern. After high pressure heat treatment with $1-6 \mathrm{GPa}$, refine granular $\alpha$ phase begin to show up and the microstructure is refined significantly. Note is the thinning effects are the most obvious when the pressure is $3 \mathrm{GPa}$. TEM observation (Fig. 3) shows that the dislocation density in $\mathrm{Cu}-\mathrm{Al}$ alloy organizations increases after pressure process. Figure 4 is $\mathrm{Cu}-\mathrm{Al}$ alloy SEM backscatter images before and after high pressure. As can be seen, there are more microscopic holes in the less compact as-cast $\mathrm{Cu}-\mathrm{Al}$ alloy matrix.
There is a significant reduce of the number of microscopic holes and holes size in the matrix after high pressure heat treatment, and compact level of the matrix increase.

Solid phase transformation involves nucleation and growth process of new phase which is controlled by atoms diffusion. Based on the diffusion theory, the grain size of the newly formed phase in $\mathrm{Cu}-\mathrm{Al}$ alloy $(d)$ can be described by following equation ${ }^{9)}$

$$
d=\lambda \sqrt{D t}
$$


where $\lambda$ is constant, $D$ is atomic diffusion coefficient, and $t$ is diffusion time.

Under high pressure, the atomic diffusion coefficient $(D)$ can be expressed as follows ${ }^{10)}$

$$
D=D_{0} e^{-p \Delta V^{*} / R T}
$$

where $D_{0}$ is constant, $P$ is pressure, $R$ is gas constant, $T$ is temperature, $\Delta V^{*}$ is activation volume.

The following equation may be expressed from eqs. (1) and (2):

$$
\ln d=-\frac{P \Delta V^{*}}{2 R T}+\frac{1}{2} \ln t+\psi
$$

where

$$
\psi=\ln \lambda+\frac{1}{2} \ln D_{0}
$$

Due to $\Delta V^{*}>0$, it can be seen from eq. (3), under the same conditions, the pressure can reduce the size of the new phase grain.

High degree of internal strain was introduced in the high pressure heat treated $\mathrm{Cu}-\mathrm{Al}$ alloy, and the density of dislocation was increased by the consequently lattice distortion, providing more place that is available for the nucleation of newly formed phase and thus increasing the nucleation rate. However, the reverse effect of high pressure on the nuclear of newly formed phase begins to dominate when the pressure is higher than certain value, in which condition the atomic diffusion is prohibited. Therefore, it is reasonable to expect that there is one high pressure that can balance the increase of nucleation rate and the decrease of atomic diffusion. The resulting nucleation and growth of new phase could be promoted mostly. In this experiment, this pressure value is $3 \mathrm{GPa}$. Under this high pressure heat treatment, the nucleation rate is highest and microstructure is finest, also, the microscopic holes in the $\mathrm{Cu}-\mathrm{Al}$ alloy matrix is closed and improve material compactness is improved by high pressure process.

\subsection{DSC curves}

Figure 5 shows DSC curves of $\mathrm{Cu}-\mathrm{Al}$ alloy before and after high pressure treatment at the constant heating rate of $5^{\circ} \mathrm{C} / \mathrm{min}$. One endothermic peak at $569.11-572.34^{\circ} \mathrm{C}$ is observed on DSC curve for each heat treatment condition. Combined with Ref. 11), this endothermic peak results from the solid-state phase transformation: $\alpha(\mathrm{Cu})+\gamma_{2}$ $\left(\mathrm{Al}_{4} \mathrm{Cu}_{9}\right) \rightarrow \beta\left(\mathrm{AlCu}_{3}\right)$.

\subsection{Thermal expansion coefficients}

Figure 6 shows the relationship between the thermal expansion coefficients of $\mathrm{Cu}-\mathrm{Al}$ alloy and temperature before and after high pressure heat treatment. It can be seen that thermal expansion coefficient of as-cast $\mathrm{Cu}-\mathrm{Al}$ alloy increases with temperature from 25 to $650^{\circ} \mathrm{C}$, but the changing trend is mild. When heat treated under high pressure, there is no change of the relationship between the thermal expansion coefficients and temperature, but in a more rapid rate. When the temperature increase to $570^{\circ} \mathrm{C}$, the thermal expansion coefficients become greater increase with temperature increasing. There is a high peak for thermal

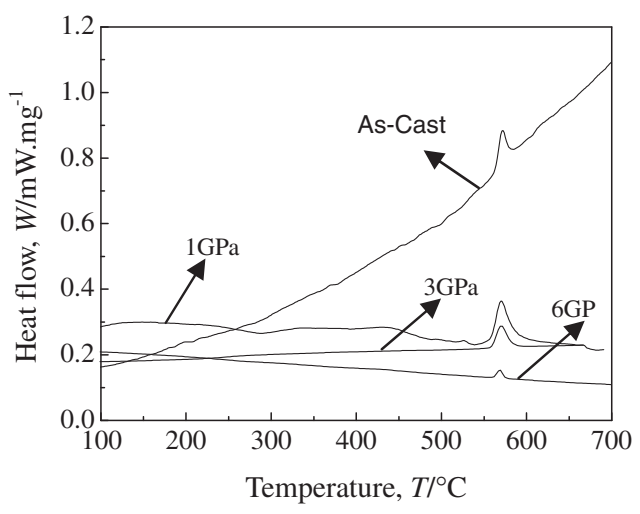

Fig. 5 DSC curves of $\mathrm{Cu}-\mathrm{Al}$ alloy at different states.

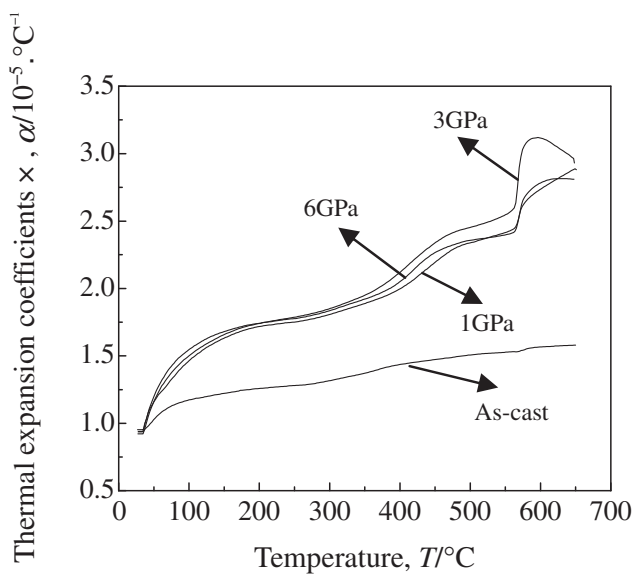

Fig. 6 Relationship curves between the thermal expansion coefficients of $\mathrm{Cu}-\mathrm{Al}$ alloy and temperature.

Table 1 The maximum thermal expansion coefficients and its corresponding temperatures of $\mathrm{Cu}-\mathrm{Al}$ alloy after different high pressure treatment.

\begin{tabular}{cccc}
\hline Pressure $/ \mathrm{GPa}$ & 1 & 3 & 6 \\
\hline Temperatures $/{ }^{\circ} \mathrm{C}$ & 631.11 & 596.37 & 649.02 \\
Thermal expansion coefficients $/ \times 10^{-5{ }^{\circ}} \mathrm{C}^{-1}$ & 2.6950 & 3.1187 & 0.28888 \\
\hline
\end{tabular}

expansion coefficient of $\mathrm{Cu}-\mathrm{Al}$ alloy at temperature of 631.11 and $596.37^{\circ} \mathrm{C}$ after heat treatment at 1 and $3 \mathrm{GPa}$, respectively. Figure 5 also reveals that there is nearly no difference of thermal expansion coefficient between different high pressure when the temperature is below around $382^{\circ} \mathrm{C}$. Above this temperature, the thermal expansion coefficient of sample after $3 \mathrm{GPa}$ high pressure treatment is higher than that of sample treated under 1 and $6 \mathrm{GPa}$, and the difference peaks at the temperature where the highest thermal coefficient arrives. The maximum thermal expansion coefficients and its corresponding temperatures for each high pressure heat treatment have been tabulated in Table 1. Note that the thermal expansion coefficient the sample after high pressure treatment is remarkably higher than that of the as-cast sample. After $3 \mathrm{GPa}$ treatment, the highest value of the thermal expansion coefficient arrives at $596.37^{\circ} \mathrm{C}$ with a value of $3.1187 \times 10^{-5 \circ} \mathrm{C}^{-1}$, which is about $99.34 \%$ higher than that value of the as-cast $\mathrm{Cu}-\mathrm{Al}$ alloy at the same temperature. 
Since the thermal expansion of the alloy is considered to be resulted by the increase of inter-atomic distance and the void in the material can be considered as a rigid phase with zero expansion coefficient ${ }^{12)}$ which shows no expansion when heated. Therefore, the voids can offset the expansion of matrix, resulting the increase of compactness of material, reduce of porosity, and finally the increase of the thermal expansion coefficient. High pressure treatment can also increase the compactness of $\mathrm{Cu}-\mathrm{Al}$ alloy and decrease the residual porosity, and therefore can increase the thermal expansion coefficient. In principle, high pressure would lead to a higher compactness and lower porosity level, and thus a high thermal expansion rate. However, Fig. 5 shows the thermal expansion coefficient of $\mathrm{Cu}-\mathrm{Al}$ alloy does not increases with the pressure in proportion, indicating that the thermal expansion coefficient is also related to the microstructure of materials (including morphology, size, content and distribution of phase). ${ }^{13}$ ) Figure 5 also reveals that the maximum thermal expansion coefficient happens when the applied high pressure is $3 \mathrm{GPa}$. As for the reasons why the thermal expansion coefficient of samples after heat treatment under $3 \mathrm{GPa}$ is higher than that of sample after other high pressure condition, and the appearance of the peak value at $\alpha$-T curve, they need further investigation.

\section{Conclusions}

(1) High pressure treatment can refine the grain of $\mathrm{Cu}-\mathrm{Al}$ alloy, and the most optimizing effect happens at $3 \mathrm{GPa}$ in the studied press range of 1 to $6 \mathrm{GPa}$.

(2) High pressure treatment can obviously increase the thermal expansion coefficient of alloy in the temperature range of $25-650^{\circ} \mathrm{C}$, but the thermal expansion coefficient doesn't increase as the pressure increases linearly.

(3) Thermal expansion coefficient of $\mathrm{Cu}-\mathrm{Al}$ alloy after $3 \mathrm{GPa}$ treatment reaches its maximum value at $596.37^{\circ} \mathrm{C}$ with a value of $3.1187 \times 10^{-5 \circ} \mathrm{C}^{-1}$, which is $99.34 \%$ higher than that of as-cast $\mathrm{Cu}-\mathrm{Al}$ alloy at the same temperature.

\section{REFERENCES}

1) G. Li, J. H. Liu, W. K. Wang and R. P. Liu: Chin. Phys. B 19 (2010) 096202.

2) Zh. X. Wang, J. B. Lu and Y. J. Xi: Mater. Sci. Eng. A 499 (2009) 192194.

3) Z. X. Wang, F. Y. Li and M. X. Pan: J. Alloy. Compd. 388 (2005) 262265.

4) H. W. Wang, D. D. Zhu, Ch. M. Zou and Z. J. Wei: Rare Metal Mater. Eng. 41 (2012) 42-44.

5) Zh. L. Wang, T. Zhang, L. Li, Y. B. Zhou, H. W. Wang and Z. J. Wei: The Chin. J. Nonfer. Metal. 22 (2012) 1006-1012.

6) Y. X, Y. F. Li, F. F. Liu, J. H. Liu and R. J. Zhang: J. Mater. Sci. Eng. A 2 (2012) 82-83.

7) L. L. Wu, L. Liu, J. H. Liu and R. J. Zhang: Mater. Trans. 53 (2012) 504-507.

8) H. Y. Wang, J. H. Liu, G. R. Peng and W. K. Wang: Chin. Phys. B 19 (2010) 096203.

9) D. Porter and K. Easterling: Phase Transformation in Metals and Alloys, (Van Nostrand Reinhold Company, New York, 1981) pp. 263284.

10) K. N. Ishihara, M. Maeda and P. H. Shingu: Acta Metall. 33 (1985) 2113-2117.

11) Zh. T. Wang: Cu Alloys and It's Working Handbook, (Central South University Press, Changsha, 2002) p. 28.

12) F. L. Yang and D. Q. Yi: J. Mech. Eng. 45 (2009) 253-257 (in Chinese).

13) B. G. Kim, S. L. Dong and Su. D. Park: Mater. Chem. Phys. 72 (2001) $42-47$. 